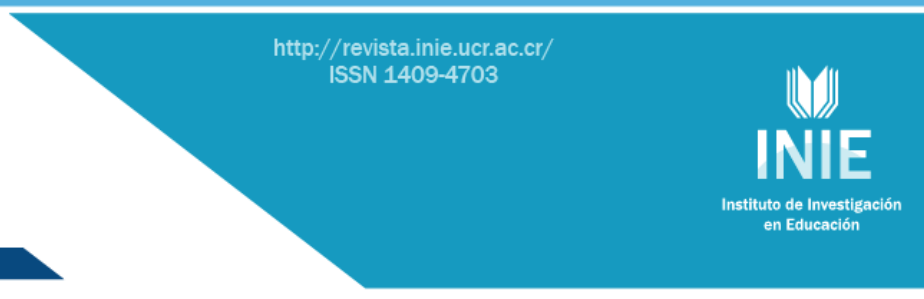

\title{
ESPERANÇAS DOCENTES EM UMA ESCOLA PÚBLICA NO OESTE DO PARANÁ, BRASIL
}

ESPERANZAS DOCENTES EN UNA ESCUELA PÚBLICA EN OESTE DE PARANÁ, BRASIL

HOPES IN A PUBLIC SCHOOL TEACHERS IN PARANÁ WEST, BRAZIL

\section{Volumen 16, Número 2}

Mayo-Agosto

pp. 1-16

\author{
Alvori Ahlert
}

Revista indizada en REDALYC,

Revista distribuida en las bases de datos:

LATINDEX, DOAJ, E-REVIST@S, IRESIE, CLASE, DIALNET, SHERPA/ROMEO, QUALIS, MIAR

Revista registrada en los directorios:

ULRICH'S, REDIE, RINACE, OEI, MAESTROTECA, PREAL, CLACSO 


\title{
ESPERANÇAS DOCENTES EM UMA ESCOLA PÚBLICA NO OESTE DO PARANÁ, BRASIL \\ ESPERANZAS DOCENTES EN UNA ESCUELA PÚBLICA EN OESTE DE PARANÁ, BRASIL \\ HOPES IN A PUBLIC SCHOOL TEACHERS IN PARANÁ WEST, BRAZIL
}

\begin{abstract}
Alvori Ahlert ${ }^{1}$
Resumo: O presente estudo discute o tema da esperança futura na profissão docente com o objetivo de identificar o nível de esperança com que as pessoas docentes enfrentam sua vida cotidiana no complexo contexto educacional da atualidade em uma escola pública no oeste do Paraná. A pesquisa foi realizada pela Linha de Pesquisa Formação de Professores do Grupo de Extensão e Pesquisa em Educação Física Escolar GEPEFE, numa escola pública no Oeste do Paraná, através de uma abordagem quantitativa, de nível descritivo. A discussão dos resultados evidencia que as pessoas docentes possuem um alto nível de esperança, acompanhada de uma auto-imagem ou auto-representação e auto-conceito que conferem grande valor ao trabalho que realizam. Trata-se de docentes que tem a dimensão afetiva e emocional para sua atividade profissional e em suas realizações como educadores e educadoras.
\end{abstract}

Palavra-chave: esperança, profissão docente, educação escolar.

Resumen: En este estudio se discute el tema de la esperanza para el futuro en la profesión docente con el fin de identificar el nivel de esperanza con que maestras y maestros enfrentan la vida cotidiana en el contexto complejo educativo de hoy, en una escuela pública en el oeste de Paraná. La pesquisa fue realizada por la Línea de Investigación de Formación Grupo de Extensión de la Enseñanza y la Investigación de la Escuela de Educación Física - GEPEFE a través de un enfoque cuantitativo, nivel descriptivo. La discusión muestra que el profesorado tiene un alto nivel de esperanza, acompañado por una imagen propia o de auto-representación y auto-concepto que conceden gran valor a su trabajo. Se trata de docentes que tienen una dimensión afectiva y emocional para sus actividades profesionales y sus logros como educadoras y educadores.

Palabras clave: ESPERANZA, PROFESIÓN DOCENTE, EDUCACIÓN.

Abstract: This study discusses the theme of hope for the future in the teaching profession in order to identify the level of hope that teachers face everyday life in today's complex educational context, a public school in western Paraná. The survey was conducted by Line Research Training Extension Group of Teachers and Research in School Physical Education - GEPEFE through a quantitative approach, descriptive level. The discussion shows that teachers have a high level of hope, accompanied by a self-image or self-representation and self-concept that attach great value to their work. These are teachers who have an affective and emotional dimension for their professional activities and their achievements as educators.

Key words: HOPE, TEACHING PROFESSION, EDUCATION.

\footnotetext{
1 Professor Associado da Universidade Estadual do Oeste do Paraná-UNIOESTE, Brasil. Pós-Doutor em Educação, Doutor em Teologia (Área: Religião e Educação), Mestre em Educação nas Ciências (Área Filosofia).
}

Dirección electrónica: alvoriahlert@yahoo.com.br

Artículo recibido: 27 de junio, 2015

Enviado a corrección: 4 de setiembre, 2015

Aprobado: 25 de abril, 2016 


\section{Introdução}

Este texto apresenta resultados de uma pesquisa sobre a esperança como uma dimensão do trabalho docente. Como um objeto subjetivo, a esperança está dentro de cada sujeito para enfrentar o cotidiano da sobrevivência, tornando-se também motivação para superar barreiras e buscar resultados para sonhos e projetos de vida. Sua relação mais intensa é com a ausência e a carência. Daí que se transforma também em combustível para lutar pela solução destas carências ao construir alternativas e criatividades, transformandose em mobilização por uma sinergia em favor da superação das dificuldades e crises.

Vivemos tempos de crise de valores, de identidades e de vazios de sentido que afetam aos profissionais da educação. Gottfried Brakemeier aponta para a esperança como principal forma de enfrentamento dessa realidade:

esperança é um dos mais poderosos antídotos contra a violência, a frustração, as drogas. [...] Cabe à educação, pois, trabalhar esse assunto. Ela estará construindo sentido exatamente assim. (Brakemeier, 2009, p. 25)

Para o teólogo Jürgen Moltmann (1971), a esperança permite o movimento, a latência, as múltiplas e inacabadas transformações das coisas. "Ela não toma as coisas como na sua estática ou inércia, mas como caminham, se movem e são mutáveis em suas possibilidades" (Moltmann, 1971, p. 13).

Diante das dores do cotidiano a esperança empurra para o movimento. Mover-se pela esperança possibilita fazer-se sujeito da história e, assim, olhar para além do existente, do igual, do preso no presente. Assim, a esperança é uma dimensão pode sustentar os cansados e sobrecarregados, marginalizados e famintos, os desiludidos e depressivos, apontando para uma parusia fora deste presente acabado e pronto. E essa espera restaura a vida certificando que o presente não é um presente contínuo, mas um aberto dialético.

Para Paulo Freire, a natureza humana constrói-se historicamente, o que significa que o ser humano é um ser sempre inacabado. E nessa consciência ele busca se tornar mais ser humano. Entretanto, esta busca esbarra nos condicionamentos históricos, mas que não é um destino fatalista, pois a história é sempre dinâmica, passível de câmbios. A história é feita pelos próprios seres humanos.

Freire reivindica a esperança como fundamental para a ação educadora:

A esperança de produzir o objeto é tão fundamental ao operário quão indispensável é a esperança de refazer o mundo na luta dos oprimidos e das oprimidas. Enquanto prática 
desveladora, gnoseológica, a educação sozinha, porém, não faz a transformação do mundo, mas esta a implica. (Freire, 1998, p. 32)

Reafirma a educação centrada no alunando como sujeito de sua aprendizagem, e convoca os educadores e as educadoras progressistas à coerência para com o sonho democrático de uma sociedade liberta, sempre respeitando o ser e o saber de alunos e alunas.

A esperança é uma variável psicológica, que vem despertando interesse em pesquisas nas últimas décadas. "A importancia da esperança na compreensão do comportamento tem sido reconhecida desde há varios anos, porém foi ao longo dos últimos anos, especialmente com o movimento da psicología positiva, que investigadores começaram a desenvolver medidas para a esperança" (Marques e Pais Ribeiro, 2006, p. 301).

Para a psicologia positiva a esperança é um sentimento de realização, de acreditar na possibilidade de algo melhor, sobretudo em contextos de enfrentamento de alguma adversidade. "Assim, a esperança é delineada em termos de probabilidades e expectativas, sendo que estas probabilidades são o produto da percepção individual, podendo 0 mesmo conjunto de factos induzir diferentes níveis e percepções da esperança, em pessoas diferentes, nas mesmas circunstâncias" (Querido, 2005, p. 25).

Os objetivos da pesquisa consistiram em investigar o tema da esperança na profissão docente, desenvolver uma abordagem teórica sobre a relação da esperança com a educação e identificar o nível de esperança com que as pessoas docentes enfrentam sua vida cotidiana no complexo contexto educacional da atualidade.

\section{Método}

A pesquisa consiste em uma abordagem quantitativa, de nível descritivo, que, segundo Edvaldo Soares, "(...) tem como objetivo primordial a descrição das características de determinada população ou fenômeno ou o estabelecimento de relações entre variáveis" (2003, p. 44). Nosso objetivo é identificar, mediante a opinião docente, os níveis de esperança docente em seu cotidiano de escola pública. "Dentre as pesquisas descritivas salientam-se aquelas que têm por objetivo estudar as características de um grupo: sua distribuição por idade, sexo, procedência, nível de escolaridade, nível de renda, estado de saúde física e mental, etc." (Soares, 2003, p. 44). 
Segundo Thomas, Nelson e Stephen (2007), a educação e as ciências comportamentais se utilizam amplamente da pesquisa descritiva. Neste sentido, apontam como metodologia de levantamento o modelo survey. "O survey geralmente tem objetivos amplos. O pesquisador procura determinar as práticas (ou opiniões) presentes em uma população específica. O survey é utilizado na educação, na psicologia, na sociologia e na atividade física." (Thomas, Nelson e Silverman, 2007, p. 235).

Participaram da pesquisa 63 professores de ambos os sexos, perfazendo o total de docentes de uma escola estadual de Ensino Fundamental e Médio, situada em uma cidade de porte médio (com aproximadamente 46 mil habitantes, conforme o Censo do IBGE/2011) da região do Oeste do Paraná.

As pessoas participantes responderam ao HERTH HOPE INDEX - TERCEIRA VERSÃO EM PORTUGUÊS, validado por Sandra Cristina Sartore (2007 Anexo 5, p. 84.) em sua Dissertação de Mestrado na Escola de Enfermagem da Universidade de São Paulo, sob a orientação da Professora Doutora Sônia Aurora Alves Grossi. A validação do referido questionário foi aprovada pelo Comitê de Ética em Pesquisa da Escola de Enfermagem da Universidade de São Paulo (CEP/EEUSP), conforme o Aneso 8 (Sartore, 2007).

$O$ instrumento de pesquisa para verificar a esperança docente no contexto educacional consistiu em responder ao questionário HERTH HOPE INDEX - TERCEIRA VERSÃO EM PORTUGUÊS. Trata-se de um inventário formado por doze questões (1. Eu estou otimista quanto à vida. 2. Eu tenho planos a curto e longo prazo. 3. Eu me sinto muito sozinho(a). 4. Eu consigo ver possibilidades em meio às dificuldades. 5. Eu tenho uma fé que me conforta. 6. Eu tenho medo do meu futuro7. Eu posso me lembrar de tempos felizes e prazerosos. 8. Eu me sinto muito forte. 9. Eu me sinto capaz de dar e receber afeto/amor. 10. Eu sei onde eu quero ir. 11. Eu acredito no valor de cada dia. 12. Eu sinto que minha vida tem valor e utilidade), que tem em sua seqüência uma escala de quatro opções, formadas pela opinião: "Discordo fortemente", "Discordo", "Concordo" e Concordo fortemente".

As pessoas docentes responderam ao questionário, retornando-o ao pesquisador em seguida. Dos 63 questionários entregues, 55 foram devolvidos integralmente preenchidos, totalizando $87,30 \%$ de participação do total do público alvo da pesquisa.

\section{Resultados e discussão}

Com relação à primeira questão, a maioria docente demonstrou otimismo (Gráfico 1). 
Gráfico 1. "Eu estou otimista quanto à vida."

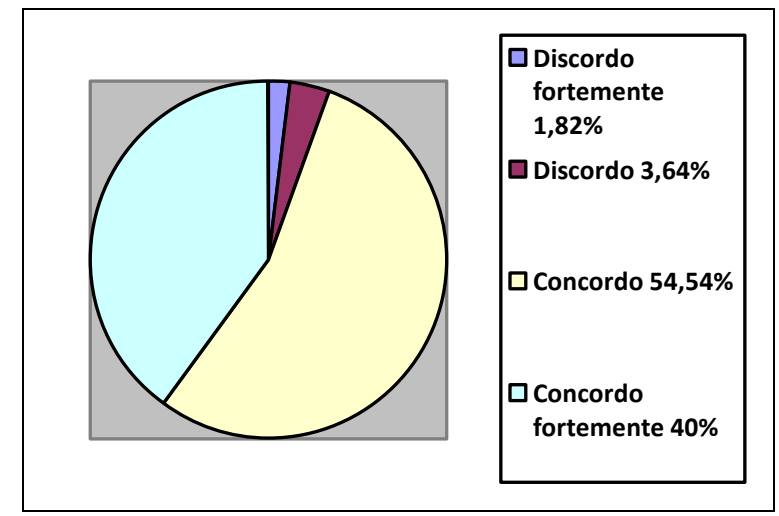

Fonte: Elaboração própria

Juntando as opiniões "Discordo fortemente" e "Discordo", apenas 5,46\% dos entrevistados afirmam não estarem otimistas com a vida. As opiniões "Concordo" e "Concordo fortemente" somam 94,54\%, o que permite afirmar um alto grau de otimismo docente com relação à vida.

$\mathrm{Na}$ segunda questão, as pessoas docentes apresentaram um alto índice de esperança futura (Gráfico 2).

Gráfico 2. "Eu tenho planos a curto e longo prazo".

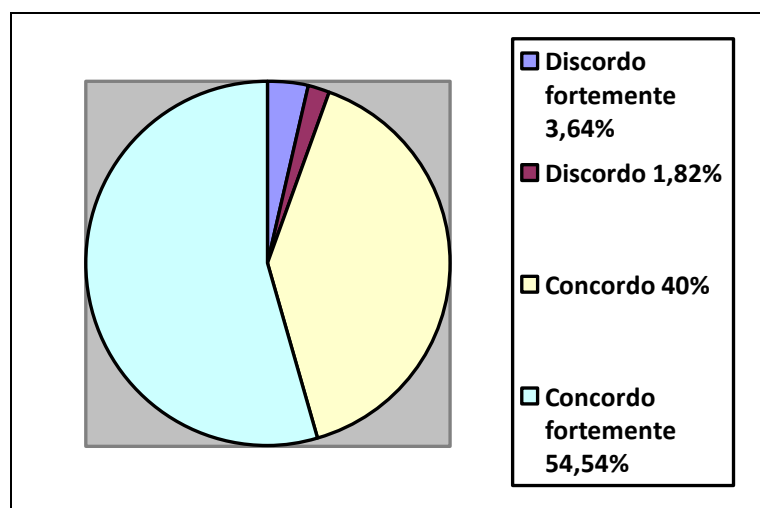

Fonte: Elaboração própria

Mais da metade, $54,54 \%$, dos profesores e das professoras, concordam fortemente em ter planos de curto e longo prazo para sua vida. Mais de $40 \%$ das pessoas entrevistadas concordam em ter estes planos. Isso nos dá o indicativo de que ampla maioria está com forte esperança no futuro, pois planejam realizações para sua vida. 
Na terceira pergunta, Eu me sinto muito sozinho(a), aparece um quadro um pouco menos esperançoso (Gráfico 3). Embora faça parte das pessoas docentes o trabalho solitário de sala de aula, percebe-se que uma parcela de $14,54 \%$ dos professores e das professoras sente-se sozinha diante de seu trabalho na escola.

Gráfico 3. "Eu me sinto muito sozinho(a)".

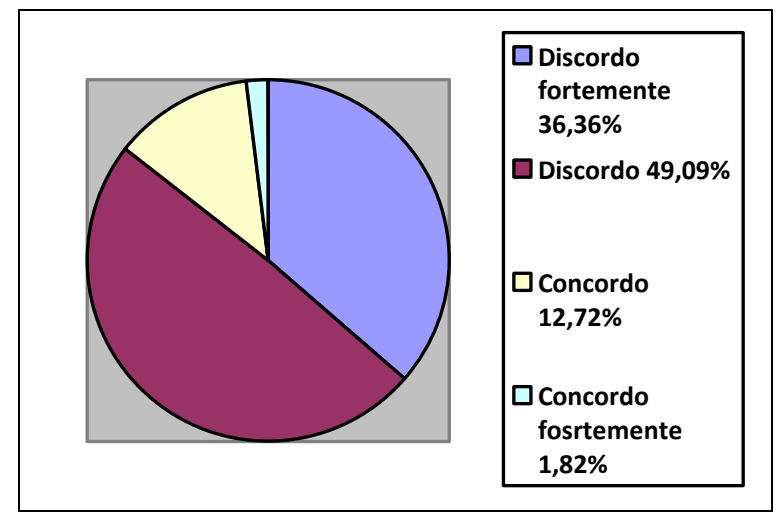

Fonte: Elaboração própria

Este ítem aponta para uma parcela do professorado que se sente só diante da tarefa complexa da sala de aula. Isto nos remete a uma fala de José Augusto Pacheco ao discorrer sobre o tema "Formação não rima com solidão". O autor questiona os processos de formação que não preparam efetivamente as professoras e os professores para a docência na sala de aula. "Onde está a formação que dispense o trabalho do profesor isolado, física e psicologicamente, na sua sala de aula, e promova a cooperação, para além da teoria? Onde está a formação que viabilize uma efetiva autonomia pedagógica?" (Pacheco, 2009, p. 100).

A quarta questão da entrevista perguntou se a professora e o professor conseguem ver posibilidades em meio às dificuldades (Gráfico 4). 
Gráfico 4. "Eu consigo ver possibilidades em meio às dificuldades."

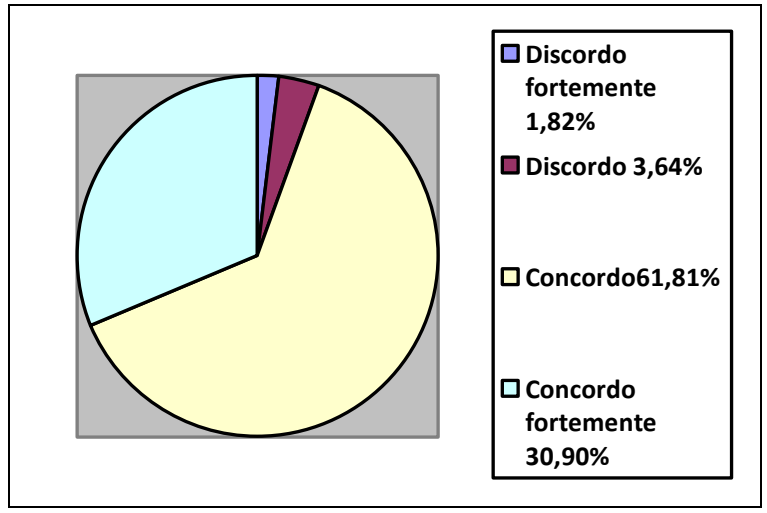

Fonte: Elaboração própria

Dos entrevistados, 30,90\% concordam fortemente de que dispõem de posibilidades em meio às dificuldades. Já $61.81 \%$ concordam enxergar posibilidades para o enfrentamento das dificuldades. 5,46\% assumem que têm dificuldades em vislumbrar posibilidades para 0 enfrentamento das dificuldades. Estes dados apontam para um relativo sentimento de fragilidade diante das dificuldades, seja pelo seu isolamento perante os problemas ou pelo conjunto de dificuldades que cada vez mais atingem os processos de ensino e aprendizagem.

Já a questão sobre "uma fé que conforta o profissional docente" revela um educador movido pela fé. Não se trata aquí apenas de uma fé religiosa, mas da fé antropológica:

a fé é uma dimensão antropológica inerente a todo o ser humano, seja cristão, budista, ateu marxista, ateu secularizado, etc. Porque a fé é uma estrutura de valores significativos para existência humana, que mostra a cada um o que deve fazer e como deve estruturar a sua vida, além de ser um princípio cognoscitivo que permite distinguir o que é importante para cada um. (Ahlert, 2008, p. 327)

A fé não é uma categoria necessariamente religiosa. Pois, antes de uma fé religiosa, existe uma fé antropológica inerente a todo o ser humano. Uma fé universal que dá sentido a fé antropológica equivale ao sentido- à vida das pessoas. Tal fé é, portanto, uma estrutura de valores significativos que orientam e dão consistência à existência do ser humano (Gráfico 5). 
Gráfico 5. "Eu tenho uma fé que me conforta."

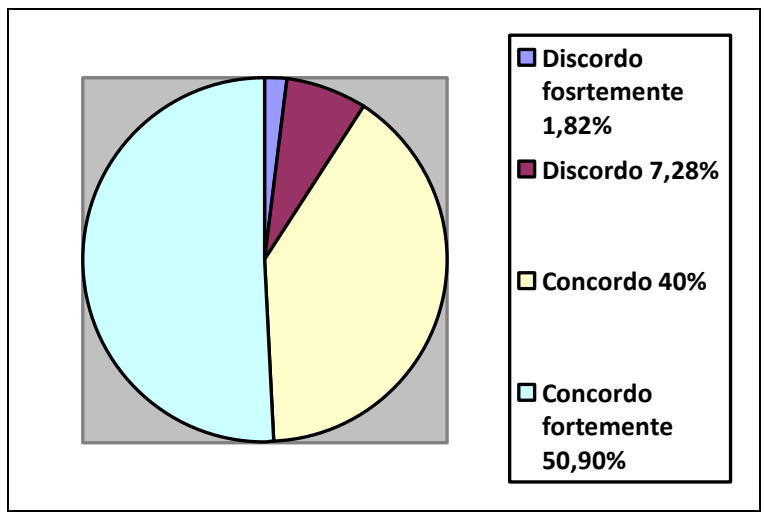

Fonte: Elaboração própria

A ampla maioria das professoras e dos professores demonstra possuir uma fé intensa como individuos na docência. 90,90\% atestam que possuem "uma fé que lhes conforta". Assim, como a busca do ser humano pela felicidade torna-se a chave antropológica, denotase que somente é possível trilhar um camino quando se coloca um objetivo na vida, um caminho que dê sentido à vida. Por isso, entendemos que é necessário que o ser humano dê uma estrutura de significação à sua vida, para alcançar um fim desejado. $E$ a grande maioria das pessoas entrevistadas afirmou que possui este instrumento a seu favor.

Quanto à percepção com relação ao futuro, denota-se uma certa insegurança em parte dos entrevistados. Para $25 \%$ o medo em relação ao futuro é uma realidade bem definida. $53,84 \%$ discordam e $21,15 \%$ discordam fortemente em ter medo com relação ao futuro. Porém, nesta questão o percentual que concorda torna-se pertinente (Gráfico 6).

Gráfico 6. "Eu tenho medo do meu futuro."

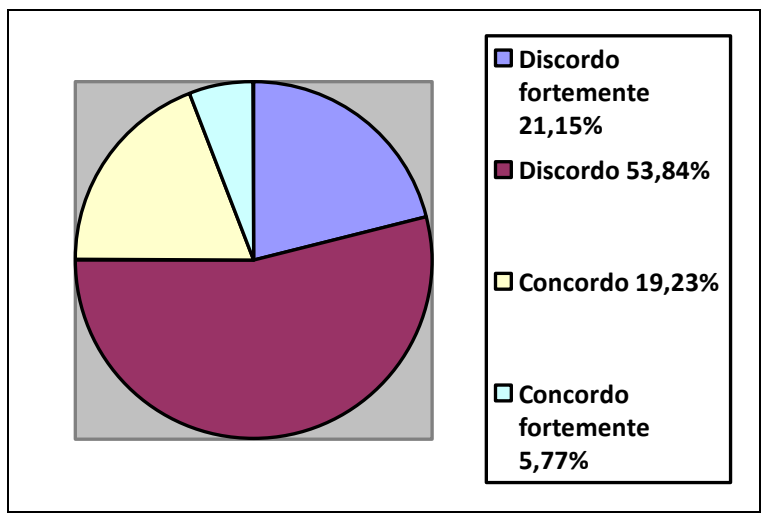

Fonte: Elaboração própria 
Cabe lembrar aqui que na atualidade existe uma série de questionamentos de professoras e professores quanto à valorização da sua função de professor/a: O que o/a professor/a ainda tem a dizer para a sociedade? Qual é o efetivo valor que esta função possui? Qual o seu futuro profissional?

O medo docente no contexto escolar já possui referenciais em várias áreas da pesquisa, como na Psicanálise. Um estudo de Maria Lígia Pompeu e Ana Archangelo (2011), atesta de que uma das categorias do medo é a perda da autoridade:

Um dos medos dos professores na atualidade, refere-se à própria fragilidade da sua profissão e à crise de autoridade docente. A perda da autoridade tem gerado insegurança, medo e a não clareza dos papéis: os professores não conseguem cumprir a sua função como professores, e os alunos pouco sabem o que estão fazendo no espaço escolar. (Pompeu e Archangelo, 2011, p. 2)

Outra categoria de medo levantada pela pesquisa é o medo de perder o controle. "Este medo esteve presente de duas formas: no medo de "fazer uma loucura" e no medo de "enlouquecer". As professoras e os professores temem que aspectos desconhecidos e "selvagens" sejam direcionados ao outro ou a si mesmos, produzindo a destruição" (Pompeu e Archangelo, p. 3). E uma terceira categoria é o medo diante do novo:

O novo apareceu nos relatos dos professores, como sendo algo que gera medo: o desconhecido apavora, gera ansiedade e temor. Arriscar-se faz parte do que é "ser humano" e, como todo risco, gera um certo medo; esse medo, porém, deveria ser um motor e não inibidor em relação à situação inusitada. (Pompeu e Archangelo, 2011, pp. 4-5)

De outro lado, o psiquiatra Lenine da Costa Ribeiro associa o medo docente à questão da violência.

O medo dos alunos, as situações de agressão e humilhação e a sensação de impotência são as queixas mais comuns nas reuniões. Fala-se sempre sobre salário ou infraestrutura das escolas, mas a insegurança do professor em relação aos alunos é um tema bem mais frequente. Os professores reclamam mais do medo que do salário. (Senra, 2014, párr. 7) 
Conseqüentemente, ter medo do futuro é compreensível quando um quarto dos entrevistados e das entrevistadas se refere a ele como realidade em sua vida profissional.

A sétima pergunta interpelou sobre lembranças de tempos felizes e prazerosos (Gráfico 7).

Gráfico 7. "Eu posso me lembrar de tempos felizes e prazerosos."

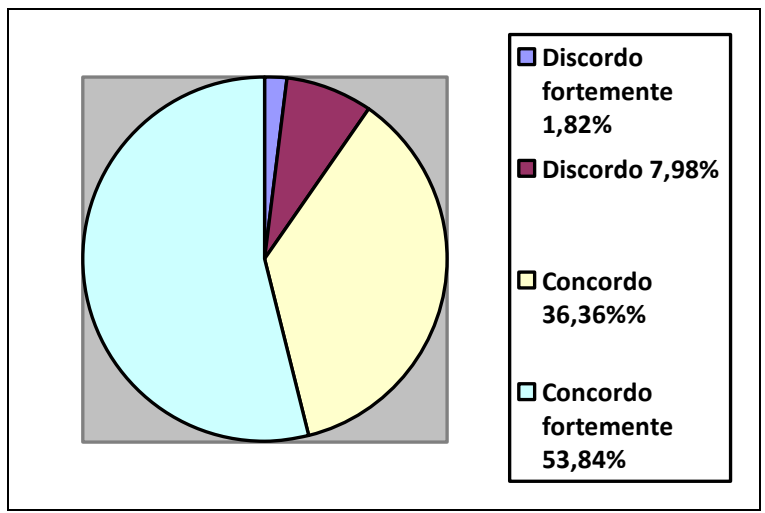

Fonte: Elaboração própria

A ampla maioria se identifica com esses tempos. Lembrar de tempos felizes e prazerosos no trabalho denota que estes profissionais trabalham com esperança em relação ao seu trabalho. Nesse contexto, Freire nos lembra que:

Há uma relação entre a alegria necessária à atividade educativa e a esperança. A esperança de professor e alunos juntos podemos aprender, ensinar, inquietar-nos, produzir e juntos igualmente resistir aos obstáculos à nossa alegria. Na verdade, do ponto de vista da natureza humana, a esperança não é algo que a ela se justaponha. (Freire, 2003, p. 72)

Do ponto de vista de lembrar tempos felizes e prazerosos, as pessoas docentes evidenciam importante nível de esperança.

No quesito quanto ao sentir-se forte, 18,19\% discordam dessa condição. Embora todo o sentimento de lembranças felizes e prazerosas uma parte das professoras e dos professores tem sentimento de fraqueza diante da grande tarefa da sala de aula (Gráfico 8). 
Gráfico 8. "Eu me sinto muito forte."

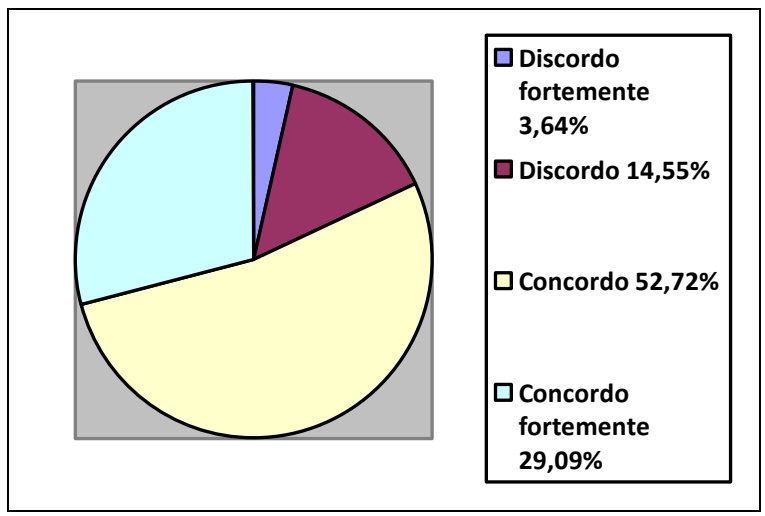

Fonte: Elaboração própria

Tal sentimento está no contexto dos sintomas de stress do professor brasileiro. Uma pesquisa desenvolvida por Maria das Graças Teles Martins evidencia que os sentimentos de impotência do professor brasileiro é um dos provocadores do stress desse profissional.

Diante da cobrança advinda da sociedade, da escola, dos pais e a própria exigência em permanecer atualizado a fim de responder às expectativas e necessidades dos alunos, conduz o professor na busca de alternativas diferenciadas para dar conta de suas atividades pedagógicas, enquanto educador. A insatisfação frente às circunstâncias desfavoráveis e os constantes desafios que necessita enfrentar provocam sentimentos de impotência, desejo de fugir de tudo, culpa, indignidade, cansaço, irritabilidade, nervosismo, desgaste físico e mental. (Martins, 2007, p. 110)

Já $81,81 \%$ concordam em sentir-se forte no contexto de sua profissão. Isto também denota uma base importante na questão de um profissional que mantém uma esperança em relação á sua prática.

A questão sobre a capacidade de dar e receber afeto/amor captou concordância em $98,17 \%$ dos entrevistados. Afeto e amor no processo educativo se concretizam através de relações de ensino e aprendizagens sustentadas no diálogo respeitoso (Gráfico 9). A construção de conhecimentos inseridos na prática cultural e na sua avaliação crítica protagoniza vivências de valores e o aprendizado no acolhimento do outro, transformando o processo educativo em humanização e desenvolvimento psicossocial e cognitivo. 
Gráfico 9. "Eu me sinto capaz de dar e receber afeto/amor."

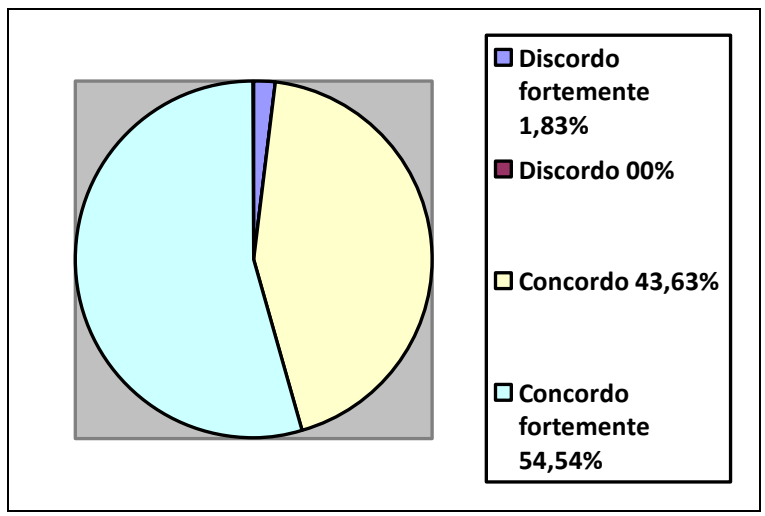

Fonte: Elaboração própria

As pessoas entrevistadas afirmam sua capacidade em receber e dar amor e afeto, constituindo-se em docentes que buscam fazer de sua prática educativa um lugar de alegria e afetividade. E isso não contradiz, de forma alguma, a necessidade de seriedade da educação e de seu rigor científico e metodológico. Freire nos alerta que a educação deve ser um processo amoroso afetivo e alegre sem prescindir a construção de conhecimentos cietíficos encharcados de esperança:

que não se pense que a prática educativa vivida com afetividade e alegria, prescinda da formação científica séria e da clareza política dos educadores ou educadoras. A prática educativa é tudo isso: afetividade, alegria, capacidade científica, domínio técnico a serviço da mudança ou, lamentavelmente, da permanência do hoje. É exatamente esta permanência do hoje neoliberal que a ideologia contida no discurso da "morte da História" propõe. (Freire, 2003, pp. 142-143)

Sobre a confiança de saber o norte de sua profissão (Eu sei onde eu quero ir), a ampla maioria, 94,54\%, afirmou saber para onde quer chegar com sua atuação (Gráfico 10). Este nos parece um dado importante na medida em que a esperança no proceso educativo traz intrinsecamente a meta e os objetivos planejados pelos profissionais da educação. 
Gráfico 10. "Eu sei onde eu quero ir."

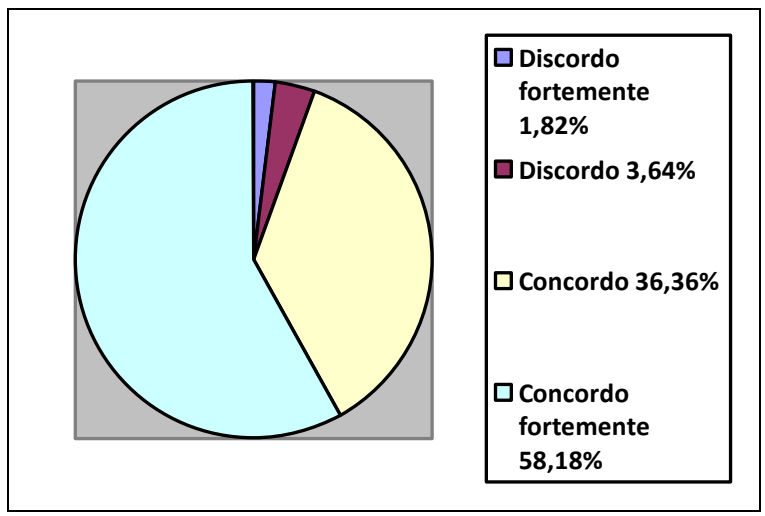

Fonte: Elaboração própria

O percentual elevado das pessoas entrevistadas em acreditar que sabem onde querem ir pode significar que o professorado tem clareza sobre seus objetivos e se colocam diante de sua profissão sem desespero, conscientes de poderem encarar os desafios, as grandes dificuldades. Para eles e elas, parece não ser difícil saber onde querem chegar com sua profissão e encaram dificuldade com bastante tranqüilidade com relação a futuro.

A questão de número 11 também teve $94.54 \%$ de respostas afirmativas (Gráfico 11).

Gráfico 11. "Eu acredito no valor de cada día."

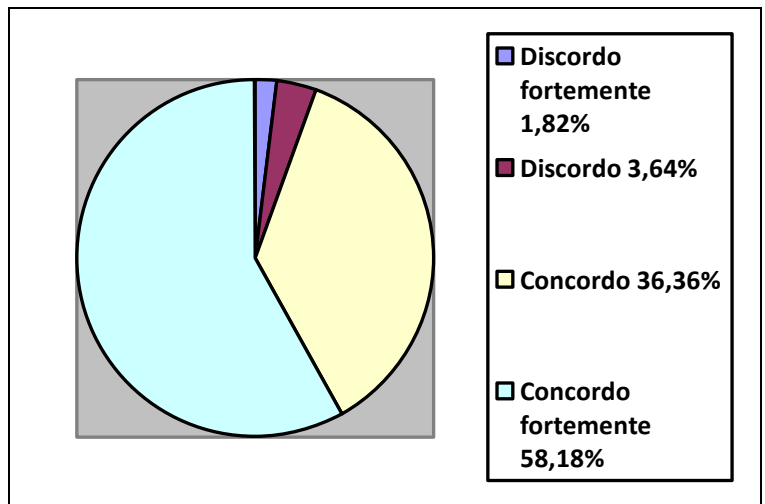

Fonte: Elaboração própria

As pessoas entrevistadas afirmam acreditar no valor de cada dia. Crer no valor de cada dia significa acreditar nos valores humanos e culturais presentes no ensino e na aprendizagem escolares. Trata-se de um importante ingrediente no conjunto da esperança docente. 
E, por último, a afirmação "Eu sinto que minha vida tem valor e utilidade" (Gráfico 12) ratifica a questão anterior. 98,17\% confirma ter este sentimento de valor e utilidade de sua vida.

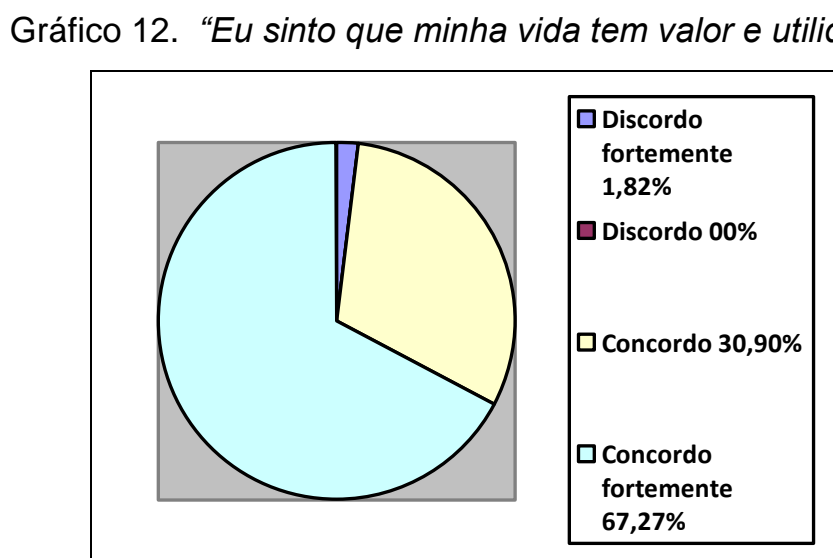

Fonte: Elaboração própria

Os dados acima denotam que as pessoas docentes possuem um autoconceito que dá muito valor ao que fazem, ao seu trabalho; que possuem uma autoimagem ou representação muito positiva de sua pessoa enquanto professoras e professores. Neste autocenceito docente está presente a dimensão afetiva e emocional, a visão sobre a ética e a moralidade de suas ações, a autonomia profissional e as realizações como educadoras e educadores.

\section{Considerações finais}

Vivemos um processo de fragmentação social capitaneado pelo liberalismo individualista que interfere em todo o processo educativo, da família à universidade. Entretanto, na escola de educação básica os problemas se evidenciam com mais intensidade. Por isso nossa pesquisa objetivou investigar o nível de esperança na profissão docente na educação básica.

$\mathrm{Na}$ primeira parte pesquisamos a importância da esperança como uma categoria no trabalho docente. Em Moltmann (1971) verificamos que a esperança absorve e sustenta as dores do cotidiano e empurra para o movimento, descortinando uma vida que se faz história e, assim, possibilita olhar para além do existente, do igual, do preso no presente. A esperança se constitui em eixo de sustento e condução para pessoas cansadas, sobrecarregadas, marginalizadas, atormentadas, desiludidas, depressivas, apontando para uma parusia fora deste presente acabado e pronto. Tal esperança pode restaurar 
cotidianamente a vida certificando que o presente não é um presente contínuo, mas um aberto dialético.

Com Freire (2000) concluímos que a matriz da esperança é a mesma da educabilidade do ser humano, compreendido como um ser sempre inacabado, um via a ser mais ser humano tornando-se um ser consciente. Daí que no processo educativo os diferentes saberes na esperança uma categoria fundamental à prática de educadores e educadoras, não importando se progressistas ou conservadores, para que se assuma que "mudar é difícil, mas é possível".

Também constatamos que a esperança é uma variável psicológica que auxilia na compreensão do comportamento profissional, pois evidencia o sentimento de realização, a capacidade de acreditar na possibilidade de algo melhor, sobretudo em contextos de enfrentamento de alguma adversidade na profissão docente.

Nossa pesquisa identificou um nível elevado de esperança entre as pessoas docentes na escola pública que demonstram forte esperança no futuro, pois planejam realizações para sua vida. Além disso, também demonstram possuir uma fé intensa como docentes, afirmando possuirem uma fé que Ihes conforta no cotidiano de suas atividades. Assim como a busca do ser humano pela felicidade torna-se a chave antropológica, professoras e professores percebem que somente é possível trilhar um camino quando se coloca um objetivo na vida, um caminho que dê sentido à vida. Por isso, entendemos que as pessoas docentes da escola pública possuem uma estrutura que dá significação à sua vida, podendo alcançar um fim desejado com seus planejamentos e metas no contexto da profissão.

De um modo geral os docentes também acreditam na sua capacidade em receber e dar amor e afeto, constituindo-se em profissionais que buscam fazer de sua prática educativa um lugar de alegria e afetividade o que, entretanto, não contradiz a necessidade de seriedade da educação e de seu rigor científico e metodológico.

Em resumo, podemos afirmar que as professoras e os professores possuem um alto nível de esperança e um auto-conceito que dá muito valor ao que fazem. Trata-se de docentes que possuem uma auto-imagem ou auto-representação muito positiva de sua pessoa enquanto profissionais da educação. Um docente que traz a dimensão afetiva e emocional para sua atividade profissional e em suas realizações como educador. 


\section{Referências}

Ahlert, Alvori. (2008). Fé e ideologia na teologia da libertação: inter-relações na obra de Juan Luis Segundo. Theologica Xaveriana, 58(166), 317-346.

Brakemeier, Gottfried. (2009). Educação e construção de sentido. Lições - Revista de Ensino e Pesquisa. Rede Sinodal de Educação, (22), 23-26.

Freire, Paulo. (1998). Pedagogia da esperança: um reencontro com a pedagogia do oprimido (5⿳亠丷厂 . ed.). Rio de Janeiro: Paz e Terra.

Freire, Paulo. (2003). Pedagogia da Autonomia: saberes necessários à prática educativa. São Paulo: Paz e Terra.

Marques, Susana e Pais Ribeiro, José Luis. (2006). Contribuição para o estudo psicométrico e estrutural da escala de esperança para crianças: estudo preliminar. In Carla Machado et al. (Eds.), Actas da XI conferência internacional de avaliação psicológica: formas e contextos (pp. 301-307). Braga: Psiquilibrios.

Martins, Maria das Graças Teles. (2007). Sintomas de Stress em Professores Brasileiros. Revista Lusófona de Educação, 10, 109-128. Recuperado de http://revistas.ulusofona.pt/index.php/rleducacao/article/view/637/532

Moltmann, Jürgen. (1971). Teologia da esperança. São Paulo: Herder.

Pacheco, José Augusto. (2009). Formação não rima com solidão. Revista Educação e Cidadania. Porto Alegre, (11), 99-109.

Pompeu, Maria Lígia e Archangelo, Ana. (2011). Medos no âmbito educacional. In O declínio dos saberes e o mercado do gozo. Recuperado de http://www.proceedings.scielo.br/scielo.php?script=sci arttext\&pid=MSC000000003201 $\underline{0000100047 \& \operatorname{lng}=\text { en\&nrm }=\text { iso }}$

Querido, Ana Isabel Fernandes. (2005). A esperança em cuidados paliativos. Universidade de Lisboa. Faculdade de Medicina de Lisboa. (Dissertação de Mestrado). Facultade de Medicina de Lisboa, Universidad de Lisboa, Portugal. Recuperado de http://iconline.ipleiria.pt/bitstream/10400.8/120/1/A\%20Esperan\%C3\%A7a\%20em\%20C uidados\%20Paliativ.pdf

Sartore, Sandra Cristina. (2007) Adaptação cultural e validação do Herth Hope Index para língua portuguesa: estudo em pacientes com doença crônica. Programa de PósGraduação em Enfermagem na Saúde do Adulto - PROESA, da Escola de Enfermagem, Universidade de São Paulo. Recuperado de http://www.teses.usp.br/teses/disponiveis/7/7139/tde-20042007-132715/pt-br.php

Senra, Ricardo. (25 agosto, 2014). Professores reclamam mais do medo que do salário, diz psiquiatra. BBC Brasil em São Paulo. Recuperado de http://www.bbc.co.uk/portuguese/noticias/2014/08/140818 salasocial eleicoes educac ao psiquiatra rs

Soares, Edvaldo. (2003). Metodologia Científica. São Paulo: Atlas.

Thomas, Jerry R., Nelson, Jack K. e Silverman, Stephen J. (2007). Métodos de pesquisa em atividade física (5a. ed.). Porto Alegre, RS: Artmed. 